\title{
Markers of activated inflammatory cells are associated with disease severity and intestinal microbiota in adults with non-alcoholic fatty liver disease
}

\author{
KATHERINE J.P. SCHWENGER ${ }^{1,2}$, LINA CHEN ${ }^{2,3}$, ADELINECHELLIAH $^{4}$, \\ HANNAH E. DA SILVA ${ }^{5}$, ANASTASIA TETERINA ${ }^{2}$, ELENA M. COMELLI ${ }^{6}$, AMEL TAIBI ${ }^{6}$, \\ BIANCA M. ARENDT ${ }^{2}$, SANDRA FISCHER ${ }^{7}$ and JOHANE P. ALLARD ${ }^{1,2}$
}

\begin{abstract}
${ }^{1}$ Department of Medicine, University of Toronto, Toronto, ON M5S 3E2; ${ }^{2}$ Department of Medicine, Toronto General Hospital, University Health Network, Toronto, ON M5G 2N2; ${ }^{3}$ Department of Pathology and Molecular Medicine, Queen's University, Kingston, ON K7L 3N6, Canada; ${ }^{4}$ Department of Pathology, University College Cork, Cork, Ireland; ${ }^{5}$ Department of Nutrition, Sunnybrook Health Sciences Center, Toronto, ON M4N 3M5; ${ }^{6}$ Department of Nutritional Sciences, University of Toronto, Toronto, ON M5S 3E2; ${ }^{7}$ Department of Pathology, Toronto General Hospital, University Health Network, Toronto, ON M5G 2N2, Canada
\end{abstract}

Received January 10, 2018; Accepted May 15, 2018

DOI: $10.3892 / \mathrm{ijmm} .2018 .3800$

\begin{abstract}
Several mechanisms contribute to the pathogenesis of non-alcoholic fatty liver disease (NAFLD). The intestinal microbiota (IM) and liver immune cells (LIC) may serve a role, but there has been no previous study assessing potential associations between IM and LIC. The aim of the present study was to investigate whether there are differences in LIC markers between patients with NAFLD and healthy controls (HC), and to determine whether these markers are associated with specific IM. The present prospective, cross-sectional study examined a cohort of adults with liver biopsy-confirmed NAFLD and HC. Clinical and laboratory data were collected. Fecal IM was assessed by quantitative polymerase chain reaction and LIC, by immunohistochemistry. NAFLD activity score (NAS) was used for disease severity. Liver immune cell counts were increased in patients with NAFLD $(n=34)$ vs. HC $(n=8)$ and this was associated with disease severity. Hematopoietic cell marker cluster of differentiation (CD) $45^{+}$and Kupffer cell marker $\mathrm{CD}_{163}{ }^{+}$were higher in NAFLD compared with HC, and those with an NAS $\geq 5$ had higher levels of $\mathrm{CD} 20^{+}$cells, a marker of B cells, vs. a NAS of 0 or 1-4. Additionally, from those patients (5 HC, 34 NAFLD), IM was measured. Specific immune cells in portal or lobular areas correlated with specific fecal IM, suggesting a potential association between IM and
\end{abstract}

Correspondence to: Dr Johane P. Allard, Department of Medicine, Toronto General Hospital, University Health Network, 585 University Avenue, Suite 9-NU-973, Toronto, ON M5G 2N2, Canada

E-mail: johane.allard@uhn.on.ca

Key words: fatty liver, immune function, intestinal microbiota, immunohistochemistry, Kupffer cells liver inflammation in patients with NAFLD. Specifically, Faecalibacterium prausnitzii was negatively correlated with $\mathrm{CD}^{+} 5^{+}(\mathrm{r}=-0.394 ; \mathrm{P}=0.015)$ and $\mathrm{CD}_{163}{ }^{+}(\mathrm{r}=-0.371 ; \mathrm{P}=0.022)$ cells in the portal tract and Prevotella was negatively correlated with $\mathrm{CD} 20^{+}(\mathrm{r}=-0.353 ; \mathrm{P}=0.028)$ cells in the liver lobule. Other taxa exhibited no correlation. In conclusion, the present study demonstrated a potential association between IM and liver inflammation in NAFLD.

\section{Introduction}

There are several mechanisms associated with the pathogenesis of non-alcoholic fatty liver disease (NAFLD) (1), including a potential role for the intestinal microbiota (IM) (2-6) and the hepatic immune system (7-9). Elevated hepatic immune cell markers such as cluster of differentiation (CD)45, CD163, CD20 and CD3 have been detected in NAFLD, mostly in pediatric studies (7-9). CD45 is a marker of hematopoietic cells (10), and an increase of CD45 indicates activation of one or more inflammatory cell types (9). CD163 is another immune cell marker, which is expressed on Kupffer cells (KCs). When activated, $\mathrm{KCs}$ produce cytokines and chemokines, contributing to hepatic injury (11). In addition, markers of B cells such as CD20 $(8,12)$ and CD3, a marker for T-cell activation (10), have been reported to be elevated in the livers of patients with NAFLD; however the results are conflicting (7-9).

Significant differences in IM have also been reported in NAFLD compared with controls (2-6). IM may contribute to NAFLD by increasing intestinal permeability which can lead to the translocation of viable bacteria and/or bacterial products across the gut mucosa (13), causing the production of pro-inflammatory cytokines and activation of hepatic inflammatory cells (14). This is supported by studies reporting elevated serum endotoxin levels in NAFLD vs. healthy controls (2). One such study investigated endotoxin and plasminogen 
activator inhibitor 1 (PAI-1) concentrations in NAFLD vs. healthy controls (HC) and demonstrated that these concentrations were higher in those with NAFLD (15). PAI-1 stimulates inflammation through upregulation of inflammatory factors, promoting inflammatory cell migration (15). Similar findings were also demonstrated in a previous pediatric study (16). In addition, translocation of bacteria can trigger an inflammatory response through the activation of Toll-like-receptor-4 (17), which in turn activates proinflammatory cytokines (18). These results suggest a role for IM in hepatic immune cell activation. To the best of our knowledge, no previous studies have assessed both IM and hepatic immune cell markers in the same patients to determine if there are associations between specific IM and immune cell markers.

The aim of the present study was to investigate whether there are differences in specific hepatic inflammatory cell markers between patients with NAFLD and HC, using the antigens CD45, CD163, CD20 and CD3, and to explore whether these markers are associated with specific IM.

\section{Materials and methods}

Methodology. The present prospective, cross-sectional study was conducted at the University Health Network (UHN; Toronto, Canada) between January 2008 and September 2012. The study protocol was approved by the UHN and University of Toronto (Toronto, Canada) Research Ethics Boards and conformed to the ethical guidelines of the 1975 Declaration of Helsinki. All participants provided informed written consent.

Subjects. A total of 42 participants were included in the present study: 12 with simple steatosis (SS), 22 with non-alcoholic steatohepatitis (NASH) and 8 with HC. Adults with persistently elevated alanine aminotransferase (ALT) levels were assessed by a hepatologist in order to rule out other causes of liver disease. Patients with biopsy-proven NAFLD were eligible for recruitment. Healthy adults undergoing assessment for live liver donation at the Living Liver Donor Transplant Program at UHN were eligible for recruitment as HC. One stool sample, fasting blood work and anthropometric measurements were collected from participants prior to liver biopsy.

Participants were excluded if they had: Liver disease other than NAFLD; end-stage liver disease; anticipated need for a liver transplant within 12 months; chronic gastrointestinal diseases; previous surgery of the gastrointestinal tract that modifies the anatomy; use of medications associated with steatosis/steatohepatitis (e.g. corticosteroids); use of pre- or probiotics within the past 6 months; use of vitamin $\mathrm{E}$ or fish oil supplements; consumption of $>20 \mathrm{~g}$ of alcohol per day; and pregnancy or lactating state.

Biochemical and clinical data. Participants' anthropometrics, smoking status, alcohol consumption habits, medication usage and samples were collected prior to the liver biopsy. The UHN Laboratory Medicine Program analyzed fasting blood samples for hemoglobin A1c, insulin, glucose, liver enzymes, lipid profile and platelets. Hemoglobin A1C in plasma was measured by ion exchange high performance liquid chromatograph (Variant II analyzer; Bio-Rad Laboratories, Inc. Hercules, CA, USA). Serum fasting insulin was determined by semi-automated immunoassay (Abbott IMX Architect i2000 system; Abbott Laboratories, Abbott Park, IL, USA). Fasting blood glucose was measured by the enzymatic hexokinase method on an Architect c8000 system (Abbott Laboratories). ALT, aspartate aminotransferase (AST) and alkaline phosphatase (ALP) in plasma were measured using an automated method on the Architect c8000 system (Abbott Laboratories). Triglycerides, total cholesterol and high-density lipoprotein (HDL) were measured using an enzymatic reaction on the Architect C16000 system (Abbott Laboratories). Low-density lipoprotein (LDL) was calculated by subtracting HDL from total cholesterol. Platelet aggregation was measured using a manual platelet aggregometer. The homeostatic model assessment-insulin resistance (HOMA-IR) was calculated using fasting serum glucose and insulin (19).

\section{Histology}

Liver histology assessment. Liver samples for patients with NAFLD were harvested using percutaneous needle biopsy, and an intraoperative wedge biopsy was obtained for $\mathrm{HC}$. Within 15 min of collection, biopsies were preserved in $10 \%$ buffered formalin for $24 \mathrm{~h}$ at room temperature, embedded in paraffin and cut into $4-5-\mu \mathrm{m}$ thick sections. Stains including hematoxylin-eosin, Masson trichrome and Perl's Prussian blue were performed at room temperature for $15 \mathrm{sec}$ and were used for the diagnosis of NAFLD, morphologic evaluation and to rule out iron loading. A single pathologist assessed the liver histology using a light microscope (020-525.024; Leica Microsystems GmbH, Wetzlar, Germany) for the presence of steatosis, inflammation and fibrosis using the validated and reproducible Brunt system (20). Additionally, the NAFLD Activity Score (NAS) was used to evaluate disease severity (21). The NAS is scored out of 8 points and includes steatosis, hepatocyte ballooning and lobular inflammation (21). Scores corresponded to level of steatosis as follows: $0,<5 \%$; $1,5-33 \% ; 2,<33-66 \%$; and 3,>66\%. Scores corresponded to level of hepatocyte ballooning as follows: 0 , no ballooning; 1 , few ballooning; and 2 prominent ballooning. Scores corresponded to level of lobular inflammation as follows; 0 , no foci; 1, $<2$ foci; 2, 2-4 foci; and 3, $>4$ foci/200x field (21).

Hepatic immune cells. The formalin-fixed paraffin-embedded liver tissue underwent immunostaining using primary monoclonal mouse antibodies raised against cell markers CD45, CD163, CD20 and CD3, as detailed in Table I. The ImmPress anti-Rabbit kit (cat. no. MP-7401; Vector Laboratories, Inc., Burlingame, CA, USA) blocking was performed at room temperature for $20 \mathrm{~min}$, and the Mach 4 (cat. no. BC-MU534G; Inter-Medico, Markham, ON, Canada) blocking was performed at room temperature for $5 \mathrm{~min}$. The serum used for all blocking was provided by the ImmPress anti-Rabbit kit (Vector Laboratories, Inc.). Staining was performed at the UHN Laboratory Medicine Program. For this, $4 \mu \mathrm{m}$ formalin-fixed paraffin-embedded sections were dewaxed at room temperature for $15 \mathrm{~min}$ in 5 changes of xylene and brought down to water through graded alcohols. Antigen retrieval or unmasking procedures were applied. Endogenous peroxidase was blocked with $3 \%$ hydrogen peroxide at room temperature for $15 \mathrm{~min}$. The detection systems used were dependent on the marker. Two detections kits were used: ImmPress anti-Rabbit kit 
Table I. Materials and methods for immunohistochemical staining.

\begin{tabular}{|c|c|c|c|c|c|c|c|c|}
\hline Antibody & Source & Cat. no. & Clonality & Pretreatment & $\begin{array}{l}\text { Antigen } \\
\text { retrieval } \\
\text { temperature }\end{array}$ & $\begin{array}{l}\text { Dilution, } \\
\text { incubation, } \\
\text { temerature }\end{array}$ & $\begin{array}{l}\text { Blocking } \\
\text { serum }\end{array}$ & $\begin{array}{c}\text { Detection } \\
\text { kit used } \\
\text { (polymer system) }\end{array}$ \\
\hline CD3 & Dako & A0452 & $\begin{array}{l}\text { Polyclonal } \\
\text { antibody }\end{array}$ & $\begin{array}{l}\text { Tris-EDTA } \\
\text { pH } 9.0\end{array}$ & $120^{\circ} \mathrm{C}$ & $\begin{array}{c}\text { 1:300, } \\
1 \mathrm{~h}, \mathrm{RT}\end{array}$ & $\begin{array}{l}2.5 \% \text { normal } \\
\text { horse serum }\end{array}$ & $\begin{array}{l}\text { Impress } \\
\text { Rabbit }\end{array}$ \\
\hline CD20 & Dako & M0755 & L26 & $\begin{array}{l}\text { Citrate } \\
\mathrm{pH} 6.0\end{array}$ & $120^{\circ} \mathrm{C}$ & $\begin{array}{c}1: 500, \\
1 \mathrm{~h}, \mathrm{RT}\end{array}$ & $\begin{array}{l}2.5 \% \text { normal } \\
\text { horse serum }\end{array}$ & MACH 4 kit \\
\hline CD45 & Dako & M0701 & $\mathrm{PD} 7+2 \mathrm{~B} 11$ & $\begin{array}{l}\text { Citrate } \\
\text { pH } 6.0\end{array}$ & $120^{\circ} \mathrm{C}$ & $\begin{array}{l}1: 1,000, \\
1 \mathrm{~h}, \mathrm{RT}\end{array}$ & $\begin{array}{l}2.5 \% \text { normal } \\
\text { horse serum }\end{array}$ & MACH 4 kit \\
\hline CD 163 & Leica & NCL-L-CD163 & 10D6 & $\begin{array}{l}\text { Citrate } \\
\mathrm{pH} 6.0\end{array}$ & $120^{\circ} \mathrm{C}$ & $\begin{array}{c}1: 200, \\
1 \mathrm{~h}, \mathrm{RT}\end{array}$ & $\begin{array}{l}2.5 \% \text { normal } \\
\text { horse serum }\end{array}$ & MACH 4 kit \\
\hline
\end{tabular}

Blocking serum provided with ImmPress anti-Rabbit kit (cat. no. MP-7401; Vector Laboratories, Inc., Burlingame, CA, USA). CD, cluster of differentiation; Dako, Dako; Agilent Technologies, Inc. (Santa Clara, CA, USA); Leica, Leica Microsystems GmbH (Wetzlar, Germany); $\mathrm{RT}$, room temperature.

(Vector Laboratories, Inc.) and Mach 4 (Inter-Medico). After following the kit instructions, color development was performed with freshly prepared 3,3'-diaminobenzidine (Dako; Agilent Technologies, Inc., Santa Clara, CA, USA). Finally, sections were counterstained lightly at room temperature for $15 \mathrm{sec}$ with Mayer's Hematoxylin, dehydrated in alcohol, cleared in xylene and mounted with Permount mounting medium (Thermo Fisher Scientific, Inc., Waltham, MA, USA). A pathologist blinded to the study groups determined the density of the cells that stained positive for the aforementioned monoclonal antibodies in both the portal tract and liver lobule. This was determined by counting the number of positive cells in 10 random portal tracts and in 10 areas of the lobular region at a magnification of x 200 under light microscopy.

Stool sample collection and measurements. A subset of 39 patients, 12 with SS, 22 with NASH and $5 \mathrm{HC}$ provided stool samples for IM. A total of 3 patients with $\mathrm{HC}$ were unable to produce stool samples and thus were excluded from this analysis. Participants provided a stool sample according to previously published methods (22). Stools samples were stored at $-80^{\circ} \mathrm{C}$ prior to analyses. Total DNA from fecal samples was extracted as previously described (6). Quantitative polymerase chain reaction (qPCR) was then performed in a $7900 \mathrm{HT}$ thermocycler (Applied Biosystems; Thermo Fisher Scientific, Inc.), using 50 ng DNA, 16S rRNA-based qPCR primers and TaqMan or Power SYBR Green 2X Master Mixes (Thermo Fisher Scientific, Inc.) to quantify total bacteria and selected groups/genera of gut microorganisms as previously described (6). These assays were adapted from the literature to target total bacteria, Bacteroidetes, Prevotella, Alistipes, Coprococcus, Ruminococcus, Clostridium leptum, C. coccoides, Lactobacillus, Faecalibacterium prausnitzii, Bifidobacterium and Escherichia coli (23-25). Most of these bacteria were chosen based on previous literature suggesting an association with NAFLD $(2-6,25)$. The specific primers used are provided in a previously published study from the present authors (25). The number of microbial cells in the fecal samples was calculated by interpolation of standard curves and expressed as colony forming unit per gram (CFU/g) of wet feces and normalized to total counts (relative abundance) as previously described (6).

Statistical analysis. Measured parameters were compared between groups using the Kruskal-Wallis test followed by Wilcoxon ranked sum, or $\chi^{2}$ and Fisher's exact test as necessary, with Bonferroni correction for multiple comparisons between diagnostic groups. $\mathrm{P}<0.05$ was considered to indicate a statistically significant difference. Spearman correlation coefficients and partial Spearman correlation coefficients were used to evaluate the association between the bacterial relative abundances and immunohistochemistry. Analysis was performed using SAS (version 9.4; SAS Institute, Inc., Cary, NC, USA) and R (version 3.2.5; https://cran.r-project. org/bin/windows/base/old/3.2.5/).

\section{Results}

Demographic and laboratory results. Table II summarizes demographic and laboratory results. Patients with SS and NASH were older and had higher AST and ALT levels compared with HC. Additionally, those with NASH had higher BMI, fasting insulin, HOMA-IR score and triglycerides compared with those with $\mathrm{HC}$.

Immunohistochemistry and liver histology. As presented in Table III and Fig. 1, patients with SS and NASH exhibited a significantly higher number of $\mathrm{CD} 45^{+}$cells in liver lobule and more $\mathrm{CD} 63^{+}$cells in the portal tract compared with $\mathrm{HC}$. Additionally, those with NASH had a significantly higher $\mathrm{CD}_{4} 5^{+}$cells in the portal tract compared with HC.

Patients were also assessed according to NAS (Table IV). Those with an NAS $\geq 5$ had a significantly higher number of $\mathrm{CD}_{4} 5^{+}$and $\mathrm{CD}_{163}{ }^{+}$cells in the portal tract compared with those with an NAS of 0 . Additionally, those with an NAS $\geq 5$ had significantly higher $\mathrm{CD} 20^{+}$cells in the liver lobule compared with those with an NAS of 0 or 1-4. Those with an NAS of 1-4 also had significantly higher $\mathrm{CD} 163^{+}$cells in the portal tract compared with those with an NAS of 0 . 
Table II. Demographic and laboratory results.

\begin{tabular}{lccc}
\hline Variables & $\mathrm{HC}(\mathrm{n}=8)$ & $\mathrm{SS}(\mathrm{n}=12)$ & $\mathrm{NASH}(\mathrm{n}=22)$ \\
\hline Sex, $\%$ male & 62.5 & 58.3 & 45.5 \\
Age (years) & $35.50(23.00,48.00)$ & $50.50(33.00,68.00)^{\mathrm{a}}$ & $45.50(29.00,61.00)^{\mathrm{a}}$ \\
BMI $\left(\mathrm{kg} / \mathrm{m}^{2}\right)$ & $26.75(23.76,35.27)$ & $26.60(23.54,37.15)$ & $31.80(24.17,49.53)^{\mathrm{a}}$ \\
Waist-to-hip ratio & $0.90(0.77,1.03)$ & $0.93(0.85,1.04)$ & $0.98(0.81,1.05)$ \\
AST (U/l) & $17.50(14.00,20.00)$ & $26.00(19.00,112.00)^{\mathrm{a}}$ & $44.00(18.00,114.00)^{\mathrm{a}, \mathrm{b}}$ \\
ALT $(\mathrm{U} / \mathrm{l})$ & $15.00(11.00,21.00)$ & $45.50(21.00,168.00)^{\mathrm{a}}$ & $68.00(22.00,141.00)^{\mathrm{a}}$ \\
ALP $(\mathrm{U} / \mathrm{l})$ & $85.00(64.00,105.00)$ & $64.50(40.00,105.00)$ & $72.50(37.00,107.00)$ \\
Glucose (mmol/l) & $5.00(4.40,6.00)$ & $5.80(4.70,11.40)$ & $5.60(4.20,7.60)$ \\
Insulin (pmol/l) & $49.00(20.00,85.00)$ & $33.00(15.00,437.00)$ & $110.00(36.00,720.00)^{\mathrm{a}}$ \\
HOMA-IR & $1.73(0.68,3.78)$ & $2.99(0.54,21.04)$ & $4.89(1.21,40.00)^{\mathrm{a}}$ \\
HbAlc & $0.05(0.05,0.06)$ & $0.06(0.05,0.09)^{\mathrm{a}}$ & $0.06(0.05,0.07)$ \\
Triglycerides (mmol/l) & $1.01(0.57,1.38)$ & $1.02(0.62,3.97)$ & $1.52(0.28,5.90)^{\mathrm{a}}$ \\
Total cholesterol (mmol/l) & $5.13(4.85,6.35)$ & $4.80(3.88,6.88)$ & $4.64(2.63,9.83)$ \\
HDL (mmol/l) & $1.33(0.83,2.07)$ & $1.28(0.95,1.72)$ & $1.12(0.34,1.60)$ \\
LDL (mmol/l) & $3.44(3.07,3.88)$ & $2.73(2.18,5.06)$ & $2.80(0.73,4.94)$ \\
\hline
\end{tabular}

Data are expressed as median (minimum, maximum) unless otherwise stated. ${ }^{\mathrm{a}} \mathrm{P}<0.05$ vs. HC, ${ }^{\mathrm{b}} \mathrm{P}<0.05$ vs. SS. HC, healthy controls; SS, simple steatosis; NASH, non-alcoholic steatohepatitis; BMI, body mass index; AST, aspartate aminotransferase; ALT, alanine aminotransferase; ALP, alkaline phosphatase; HOMA-IR, homeostatic model assessment-insulin resistance; HbA1c, hemoglobin A1c; HDL, high density lipoprotein; LDL, low density lipoprotein.

Table III. Immunohistochemistry by diagnosis of liver disease.

\begin{tabular}{lccc}
\hline Parameters & $\mathrm{HC}(\mathrm{n}=8)$ & $\mathrm{SS}(\mathrm{n}=12)$ & $\mathrm{NASH}(\mathrm{n}=22)$ \\
\hline CD45P & $21.1(6.6,42.7)$ & $53.8(10.8,94.9)$ & $45.0(12.1,189.0)^{\mathrm{a}}$ \\
CD45L & $122.1(45.3,155.0)$ & $148.7(78.3,196.4)^{\mathrm{a}}$ & $139.7(102.9,221.8)^{\mathrm{a}}$ \\
CD3P & $25.8(7.9,43.5)$ & $38.3(7.4,95.8)$ & $32.6(8.8,144.0)$ \\
CD3L & $53.2(30.0,86.6)$ & $67.8(30.3,112.3)$ & $62.2(21.7,119.0)$ \\
CD20P & $1.5(0.3,7.9)$ & $5.3(0.2,19.2)$ & $5.1(0.1,63.9)$ \\
CD20L & $5.2(1.7,8.2)$ & $4.5(1.7,10.7)$ & $6.1(2.3,23.0)$ \\
CD163P & $1.4(0.0,4.0)$ & $5.8(0.0,28.7)^{\mathrm{a}}$ & $5.7(1.3,24.4)^{\mathrm{a}}$ \\
CD163L & $149.6(37.0,226.3)$ & $132.2(43.3,226.3)$ & $137.9(65.5,264.1)$ \\
\hline
\end{tabular}

Data are expressed as median (minimum, maximum). ${ }^{\text {a }}<0.05$ vs. HC. HC, healthy controls; SS, simple steatosis; NASH, non-alcoholic steatohepatitis; $\mathrm{CD}$, cluster of differentiation; L, cell counts of liver lobule; $\mathrm{P}$, cell counts of portal tract.

Immunohistochemistry, intestinal microbiota and liver histology. A subset of 39 patients, 12 with SS, 22 with NASH and $5 \mathrm{HC}$ provided stool samples for IM. Correlations between CD cell counts and specific bacteria taxa are presented in Table V. In the entire cohort, $F$. prausnitzii was significantly negatively correlated with $\mathrm{CD}^{4} 5^{+}$(Fig. 2) and $\mathrm{CD} 163^{+}$(Fig. 3) cells in the portal tract. Prevotella was significantly negatively correlated (Fig. 4) with the CD20 $0^{+}$cell count in the liver lobule. Other taxa did not correlate.

Subsequently, the correlation of IM and immunohistochemistry was investigated based on histological diagnosis (Table VI). It was demonstrated that $F$. prausnitzii was negatively correlated with CD163P in patients with SS, however this was not significant in patients with NASH or HC. Finally, it was demonstrated that Bifidobacterium was negatively correlated with $\mathrm{CD} 20^{+}$and $\mathrm{CD}_{163}{ }^{+}$cell counts in the portal tract in patients with SS.

\section{Discussion}

The present results demonstrate that patients with NAFLD have elevated CD cell markers that are associated with disease severity. In addition, some of these CD cell markers are associated with the relative abundance of specific bacterial taxa in feces, particularly $F$. prausnitzii, Prevotella and Bifidobacterium. To the best of our knowledge, this finding has not been reported before and requires further investigation. Very few previous studies, mostly pediatric, (7-9) demonstrated 
Table IV. Immunohistochemistry by NAS.

\begin{tabular}{lcrr}
\hline Parameters & NAS $=0(\mathrm{n}=8)$ & NAS $1-4(\mathrm{n}=22)$ & NAS $\geq 5(\mathrm{n}=11)$ \\
\hline CD45P & $21.1(6.6,42.7)$ & $46.5(10.8,102.8)$ & $47.3(30.7,189.0)^{\mathrm{a}}$ \\
CD45L & $122.1(45.3,155.0)$ & $144.4(78.3,196.4)$ & $133.4(111.5,221.8)$ \\
CD3P & $25.8(7.9,43.5)$ & $27.4(7.4,106.4)$ & $37.8(25.2,144.0)$ \\
CD3L & $53.2(30.0,86.6)$ & $65.6(24.75,119.0)$ & $68.9(21.7,112.3)$ \\
CD20P & $1.5(0.3,7.9)$ & $4.2(0.1,30.3)$ & $5.5(2.4,63.9)$ \\
CD20L & $5.2(1.7,8.2)$ & $4.9(1.7,11.2)^{\mathrm{a}}$ & $7.40(3.8,23.0)^{\mathrm{a}, \mathrm{b}}$ \\
CD163P & $1.4(0.0,4.0)$ & $5.2(0.0,28.7)^{\mathrm{a}}$ & $6.3(2.6,19.5)^{\mathrm{a}}$ \\
CD163L & $149.6(37.0,226.3)$ & $159.5(43.3,264.1)$ & $121.4(65.5,157.7)$ \\
\hline
\end{tabular}

Data are expressed as median (minimum, maximum). ${ }^{\mathrm{a}} \mathrm{P}<0.05 \mathrm{vs} . \mathrm{HC},{ }^{\mathrm{b}} \mathrm{P}<0.05 \mathrm{vs}$. SS. NAS, non-alcoholic fatty liver disease score; $\mathrm{CD}$, cluster of differentiation; L, cell counts of liver lobule; $\mathrm{P}$, cell counts of portal tract.
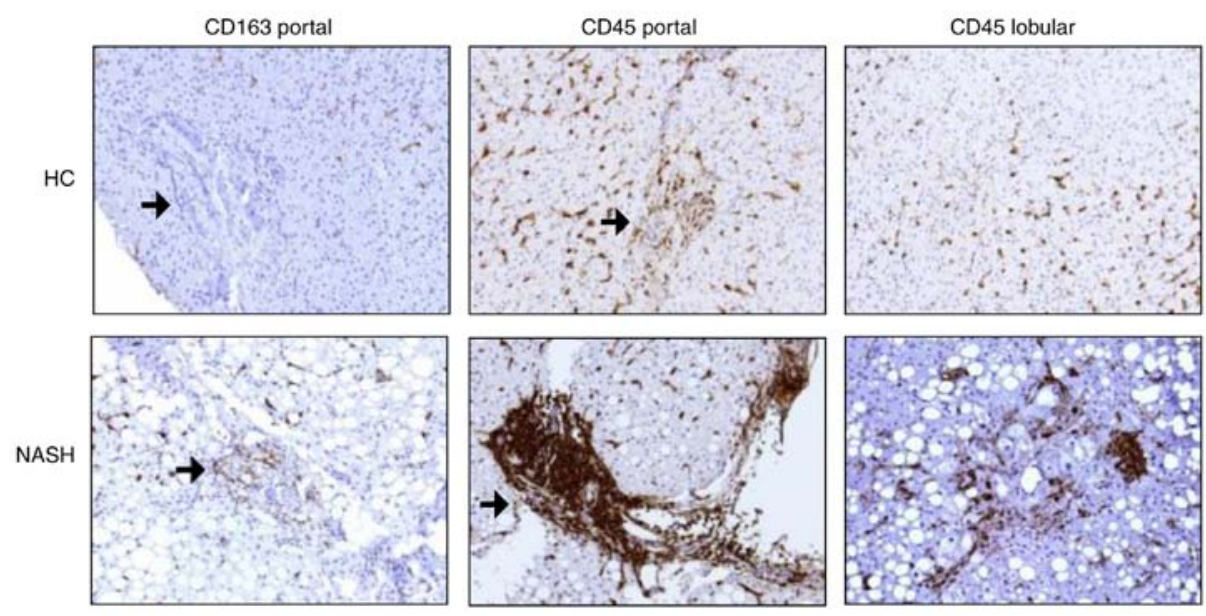

Figure 1. Immunohistochemical labeling for CD163 and CD45 in liver biopsies of HC and patients with NASH at x200 magnification. Portal tracts (arrows) and lobules in $\mathrm{HC}$ exhibit a lower number of $\mathrm{CD} 163^{+} / \mathrm{CD} 45^{+}$cells compared with samples with NASH. CD, cluster of differentiation; HC, healthy controls; NASH, non-alcoholic steatohepatitis.

elevation of specific CD markers in NAFLD as well as associations with disease severity. Other studies demonstrated differences in IM between NAFLD and HC $(2,3,5,13)$, and associations with disease severity (26). However, none have assessed both parameters in the same patients to determine if there are potential associations between hepatic immune cells and specific IM.

Previous evidence supports a role for the immune system in the progression of NAFLD (17). In accordance with previous findings, $(7,9)$ the present study demonstrated that patients with NAFLD, specifically NASH, had significantly higher numbers of total immune cell population $\left(\mathrm{CD} 45^{+}\right)$ in both the lobule and the portal tract when compared with controls. However, the number of $\mathrm{KCs}\left(\mathrm{CD} 163^{+}\right)$was higher only in the portal tract, and there was no significant difference in the numbers of $\mathrm{T}$ cells or B cells in either portal or lobular areas between $\mathrm{HC}$ and SS/NASH. The present data also demonstrated that patients with higher NAS had altered numbers of total immune cell population $\left(\mathrm{CD} 45^{+}\right)$and $\mathrm{KCs}$ $\left(\mathrm{CD}_{163}{ }^{+}\right)$, but only in the portal tract. Although NAFLD is histologically assessed based on lobular features of inflammation, portal inflammatory infiltrate was previously

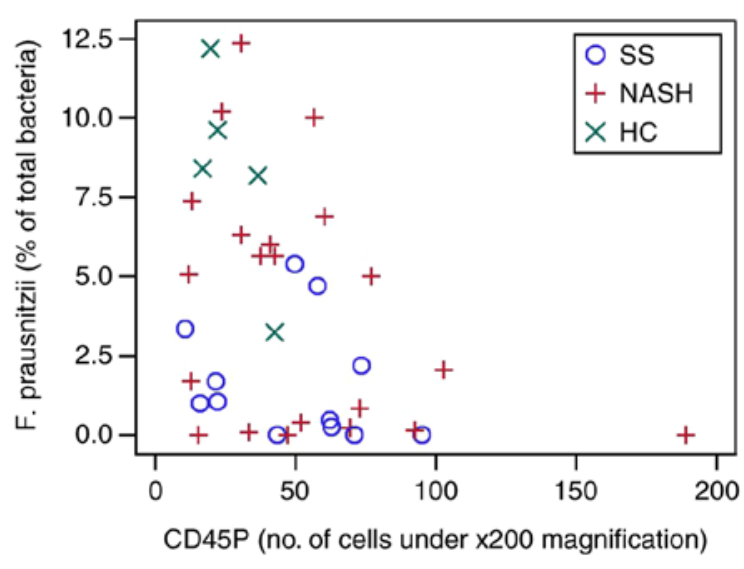

Figure 2. F. prausnitzii was negatively correlated with $\mathrm{CD} 45 \mathrm{P}^{+}$. CD, cluster of differentiation; $\mathrm{P}$, cell counts of portal tract; SS, simple steatosis; NASH, non-alcoholic steatohepatitis; HC, healthy controls.

studied by Gadd et al (8) because of its role in the development of portal fibrosis. In that study, the presence of portal inflammation was strongly correlated with fibrosis stage (8). 


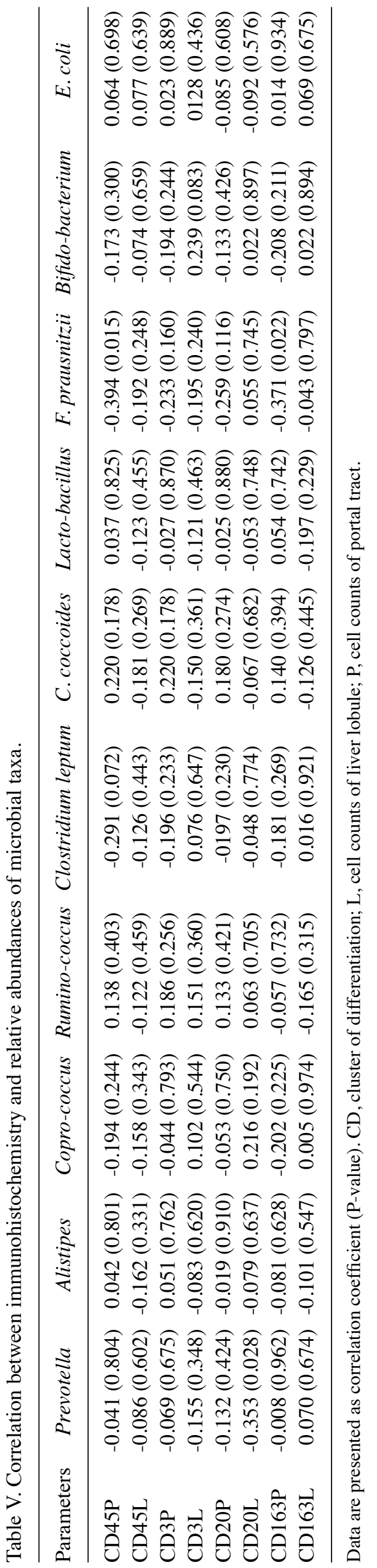

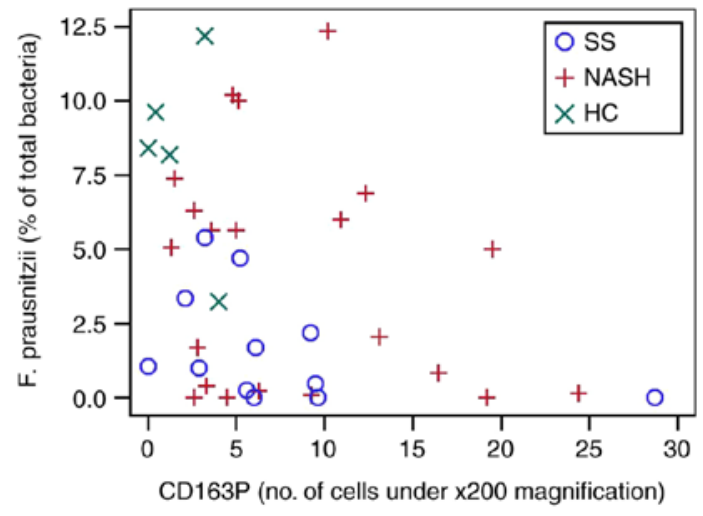

Figure 3. F. prausnitzii was negatively correlated with $\mathrm{CD}_{163 \mathrm{P}^{+}} . \mathrm{CD}$, cluster of differentiation; $\mathrm{P}$, cell counts of portal tract; SS, simple steatosis; NASH, non-alcoholic steatohepatitis; HC, healthy controls.

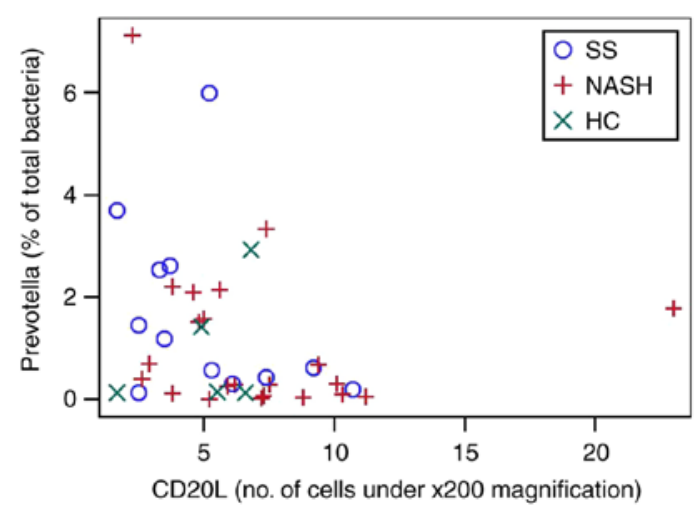

Figure 4. Prevotella was negatively correlated with $\mathrm{CD}_{2} 0 \mathrm{~L}^{+} . \mathrm{CD}$, cluster of differentiation; L, cell counts of liver lobule; SS, simple steatosis; NASH, non-alcoholic steatohepatitis; HC, healthy controls.

Additionally, using immunostaining for broad leukocyte subset markers (CD68, CD3, CD8, CD4, CD20 and neutrophil elastase) and selected inflammatory markers, it was observed that cells expressing all markers examined were identified throughout the liver lobules and in portal tracts. Portal tracts were more densely populated by these cells, and the population was dominated by CD 68 macrophages and CD8 lymphocytes at all stages of disease (8). As in that previous study, the present findings also demonstrated that the number of $\mathrm{B}$ cells $\left(\mathrm{CD} 20^{+}\right)$was higher in the liver lobules of those with higher NAS scores, but there was no significant difference in $\mathrm{T}$ cell $\left(\mathrm{CD}^{+}\right)$counts in either the lobular or the portal area. $\mathrm{CD} 20^{+}$and $\mathrm{CD}^{+}$cells levels were also not significantly different between NAFLD and HC. In contrast, one previous pediatric study revealed lower $\mathrm{CD}^{+}$ in children with NASH (9). Notably, two other human studies identified that the intrahepatic ratio of $\mathrm{CD}^{+} / \mathrm{CD} 56^{+}$cells was increased in patients with NAFLD with more severe liver disease $(27,28)$. One previous study, using flow cytometric analysis, demonstrated that as NAS increased so did the amount of intrahepatic $\mathrm{CD}^{+} / \mathrm{CD}^{2} 6^{+}$cells (28), whereas another study indicated that the percentage of intrahepatic $\mathrm{CD}^{+} / \mathrm{CD} 56^{+}$cells was significantly higher in patients with moderate to severe steatosis when compared with those with mild and no steatosis (27). Therefore, one of the reasons that 
Table VI. Correlation between immunohistochemistry and relative abundances of microbial taxa based on non-alcoholic fatty liver disease diagnosis.

\begin{tabular}{|c|c|c|c|c|}
\hline Taxa & CD cell & Diagnosis & $\begin{array}{l}\text { Correlation } \\
\text { coefficient }\end{array}$ & P-value \\
\hline \multirow[t]{6}{*}{ F. prausnitzii } & \multirow[t]{3}{*}{ CD45P } & $\mathrm{HC}$ & -0.700 & 0.188 \\
\hline & & SS & -0.399 & 0.199 \\
\hline & & NASH & -0.309 & 0.174 \\
\hline & \multirow[t]{3}{*}{ CD163P } & $\mathrm{HC}$ & -0.300 & 0.624 \\
\hline & & SS & -0.594 & 0.042 \\
\hline & & NASH & -0.144 & 0.535 \\
\hline \multirow{6}{*}{ Bifidobacterium } & \multirow[t]{3}{*}{ CD20P } & $\mathrm{HC}$ & 0.700 & 0.188 \\
\hline & & SS & -0.615 & 0.033 \\
\hline & & NASH & 0.001 & 0.996 \\
\hline & \multirow[t]{3}{*}{ CD163P } & $\mathrm{HC}$ & 0.500 & 0.391 \\
\hline & & SS & -0.608 & 0.036 \\
\hline & & NASH & -0.127 & 0.582 \\
\hline \multirow[t]{3}{*}{ Prevotella } & \multirow[t]{3}{*}{ CD20L } & $\mathrm{HC}$ & 0.300 & 0.624 \\
\hline & & SS & -0.431 & 0.162 \\
\hline & & NASH & -0.367 & 0.093 \\
\hline
\end{tabular}

$\mathrm{CD}$, cluster of differentiation; HC, healthy controls; SS, simple steatosis; NASH, non-alcoholic steatohepatitis; L, cell counts of liver lobule; P, cell counts of portal tract.

a significant difference was not observed in in $\mathrm{CD}^{+}$cells is because the differences are seen in a cell subgroup.

In regard to $\mathrm{CD}_{4} 5^{+}$and $\mathrm{CD} 163^{+}$, the present results were also comparable to others. Previous pediatric studies $(7,9)$ have identified increased numbers of CD $45^{+}$and $\mathrm{CD} 163^{+}$ cells in children with greater disease severity, and another study in adults revealed that activated $\mathrm{KCs}\left(\mathrm{CD} 163^{+}\right)$contributed to the development of NASH (29). However, a recent study of 45 individuals with NAFLD undergoing bariatric surgery identified no difference in the intrahepatic numbers of $\mathrm{CD}_{163}{ }^{+}$between those with and without NASH (30), thereby suggesting that perhaps patients with morbid obesity are different. In the present study, higher $\mathrm{CD} 63^{+}$cell counts were observed in NAFLD vs. HC, and an association was identified with disease severity as previously reported in pediatric patients (9).

Taken together, these results suggest that in NAFLD there is an infiltration of inflammatory cells that is associated with disease severity, suggesting a possible role in the pathogenesis of the disease. Previous research suggests that altered IM, which has been demonstrated in NAFLD $(2,3,5,6,13,26)$, may serve a role in pathogenesis through bacterial translocation leading to systemic chronic inflammation (31), which has the potential to activate hepatic inflammatory cells through the production of cytokines. Using qPCR to evaluate several bacterial taxa, it was demonstrated that $F$. prausnitzii, Prevotella and Bifidobacterium were negatively correlated with specific CD cell markers. $F$. prausnitzii was the most abundant bacterium in the healthy IM, and as hypothesized, was revealed to be negatively correlated with hepatic immune cells (32). In animal models, $F$. prausnitzii has been demonstrated to have anti-inflammatory effects $(33,34)$ and is also reported to be low in other human inflammatory conditions such as inflammatory bowel disease (34). Therefore, lower $F$. prausnitzii may have a role in the higher hepatic inflammatory cell infiltrate. Prevotella, which produces high levels of short-chain fatty acids (SCFAs), has been identified in lower abundance in individuals with NASH $(13,26)$ and SCFAs have been reported to have an anti-inflammatory effect (35), supporting a role for Prevotella. Bifidobacterium is another SCFA producer that has been reported to be reduced in NASH (2). SCFAs have been demonstrated to protect against gut inflammation (36).

The strengths of the present study are the defined characterization of the study subjects with liver histology and the quantification of specific bacterial taxa reported to be associated with NAFLD. Another is that liver immunostaining allowed for the assessment of associations between IM and CD markers. The limitations include the cross-sectional design, which does not indicate causality and the small sample size due to the invasiveness of the liver biopsy. However, similar studies assessing immunohistochemistry in NAFLD had comparable samples sizes $(8,9)$ but did not include IM assessment. The association reported between immune cell infiltrate and IM is based on associations and does not prove causality. Additional studies are required to determine the role of specific bacterial taxa in the immunopathogenesis of NAFLD.

In conclusion, the present findings indicated that B cells and Kupffer cells, but not T cells, were associated with NAFLD and disease severity, and specific immune cells in portal or lobular areas were correlated with specific gut microbial taxa, particularly Faecalibacterium prausnitzii. Future research should investigate the specific immune cell subgroups, inflammatory mediators and IM during intervention studies to further explore their roles in NAFLD pathogenesis. 


\section{Acknowledgements}

EMC holds the Lawson Family Chair in Microbiome Nutrition Research at the University of Toronto. This abstract was presented at the Canadian Digestive Diseases Week, on February 9th 2018 at the Fairmount Royal York (Toronto, Canada), and was published as Abstract 1.

\section{Funding}

The present study was funded through operating grants from the Canadian Institutes of Health Research (grant nos. NMD-86922 and MOP-89705) and the 2012 American College of Gastroenterology Clinical Research Award. Some of the equipment used in the present study was supported by the 3D (Diet, Digestive Tract and Disease) Centre, funded by the Canadian Foundation for Innovation and Ontario Research Fund (grant nos. 19442 and 30961).

\section{Availability of data and materials}

The datasets used and/or analyzed during the current study are available from the corresponding author on reasonable request.

\section{Authors' contributions}

KJPS helped analyze and interpret statistical data and was a major contributor to writing of manuscript. LC performed study conception and design, drafting manuscript and critical revision. AC performed acquisition of immune cell data. HEDS performed acquisition of patient clinical and biochemical data. ATe performed analysis and interpretation of statistical data. EMC performed study conception and design, drafting of manuscript and critical revision. Ata performed acquisition of microbiota data and drafting of manuscript. BMA performed study conception and design, acquisition of clinical and biochemical data. SF performed study conception and design, analysis and interpretation of histological data, drafting of manuscript and critical revision. JPA performed study conception and design, analysis and interpretation of statistical data, drafting of manuscript and critical revision and supervised entire project. All authors read and approved the final manuscript.

\section{Ethics approval and consent to participate}

The present study protocol was approved by the University Health Network (Toronto, Canada) and University of Toronto (Toronto, Canada) Research Ethics Boards and conformed to the ethical guidelines of the 1975 Declaration of Helsinki. All participants gave their informed written consent.

\section{Patient consent for publication}

All participants gave their informed written consent.

\section{Competing interests}

The authors declare that they have no competing interests.

\section{References}

1. Review Team; LaBrecque DR, Abbas Z, Anania F, Ferenci P, Khan AG, Goh KL, Hamid SS, Isakov V, Lizarzabal M, et al: World Gastroenterology Organisation global guidelines: Nonalcoholic fatty liver disease and nonalcoholic steatohepatitis. J Clin Gastroenterol 48: 467-473, 2014.

2. Zhu L, Baker SS, Gill C, Liu W, Alkhouri R, Baker RD and Gill SR: Characterization of gut microbiomes in nonalcoholic steatohepatitis (NASH) patients: A connection between endogenous alcohol and NASH. Hepatology 57: 601-609, 2013.

3. Wong VW, Tse CH, Lam TT, Wong GL, Chim AM, Chu WC, Yeung DK, Law PT, Kwan HS, Yu J, et al: Molecular characterization of the fecal microbiota in patients with nonalcoholic steatohepatitis-a longitudinal study. PLoS One 8: e62885, 2013.

4. Spencer MD, Hamp TJ, Reid RW, Fischer LM, Zeisel SH and Fodor AA: Association between composition of the human gastrointestinal microbiome and development of fatty liver with choline deficiency. Gastroenterology 140: 976-986, 2011.

5. Raman M, Ahmed I, Gillevet PM, Probert CS, Ratcliffe NM, Smith S, Greenwood R, Sikaroodi M, Lam V, Crotty P, et al: Fecal microbiome and volatile organic compound metabolome in obese humans with nonalcoholic fatty liver disease. Clin Gastroenterol Hepatol 11: 868-875.e1-e3, 2013.

6. Mouzaki M, Comelli EM, Arendt BM, Bonengel J, Fung SK, Fischer SE, McGilvray ID and Allard JP: Intestinal microbiota in patients with nonalcoholic fatty liver disease. Hepatology 58: 120-127, 2013.

7. Nobili V, Cutrera R, Liccardo D, Pavone M, Devito R, Giorgio V, Verrillo E, Baviera G and Musso G: Obstructive sleep apnea syndrome affects liver histology and inflammatory cell activation in pediatric nonalcoholic fatty liver disease, regardless of obesity/insulin resistance. Am J Respir Crit Care Med 189: 66-76, 2014.

8. Gadd VL, Skoien R, Powell EE, Fagan KJ, Winterford C, Horsfall L, Irvine $\mathrm{K}$ and Clouston AD: The portal inflammatory infiltrate and ductular reaction in human nonalcoholic fatty liver disease. Hepatology 59: 1393-1405, 2014.

9. De Vito R, Alisi A, Masotti A, Ceccarelli S, Panera N, Citti A, Salata M, Valenti L, Feldstein AE and Nobili V: Markers of activated inflammatory cells correlate with severity of liver damage in children with nonalcoholic fatty liver disease. Int $\mathbf{J}$ Mol Med 30: 49-56, 2012.

10. Torlakovic EE, Naresh K, Kremer M, van der Walt J, Hyjek E and Porwit A: Call for a European programme in external quality assurance for bone marrow immunohistochemistry; report of a European Bone Marrow Working Group pilot study. J Clin Pathol 62: 547-551, 2009.

11. Arrese M, Cabrera D, Kalergis AM and Feldstein AE: Innate immunity and inflammation in NAFLD/NASH. Dig Dis Sci 61: 1294-1303, 2016.

12. Caldeira PC, Oliveira e Silva KR, Vidigal PV, Grossmann Sde M and do Carmo MA: Inflammatory cells in minor salivary glands of patients with chronic hepatitis C: Immunophenotype, pattern of distribution, and comparison with liver samples. Hum Immunol 75: 422-427, 2014.

13. Jiang W, Wu N, Wang X, Chi Y, Zhang Y, Qiu X, Hu Y, Li J and Liu Y: Dysbiosis gut microbiota associated with inflammation and impaired mucosal immune function in intestine of humans with non-alcoholic fatty liver disease. Sci Rep 5: 8096, 2015.

14. Kudo H, Takahara T, Yata Y, Kawai K, Zhang W and Sugiyama T: Lipopolysaccharide triggered TNF-alpha-induced hepatocyte apoptosis in a murine non-alcoholic steatohepatitis model. J Hepatol 51: 168-175, 2009.

15. Thuy S, Ladurner R, Volynets V, Wagner S, Strahl S, Königsrainer A, Maier KP, Bischoff SC and Bergheim I: Nonalcoholic fatty liver disease in humans is associated with increased plasma endotoxin and plasminogen activator inhibitor 1 concentrations and with fructose intake. The J Nutr 138: 1452-1455, 2008.

16. Alisi A, Manco M, Devito R, Piemonte F and Nobili V: Endotoxin and plasminogen activator inhibitor-1 serum levels associated with nonalcoholic steatohepatitis in children. J Pediatr Gastroenterol Nutr 50: 645-649, 2010.

17. Ganz M and Szabo G: Immune and inflammatory pathways in NASH. Hepatol Int 7 (Suppl 2): S771-S781, 2013.

18. Aron-Wisnewsky J, Gaborit B, Dutour A and Clement K: Gut microbiota and non-alcoholic fatty liver disease: New insights. Clin Microbiol Infect 19: 338-348, 2013. 
19. Matthews DR, Hosker JP, Rudenski AS, Naylor BA, Treacher DF and Turner RC: Homeostasis model assessment: Insulin resistance and beta-cell function from fasting plasma glucose and insulin concentrations in man. Diabetologia 28: 412-419, 1985.

20. Brunt EM, Janney CG, Di Bisceglie AM, Neuschwander-Tetri BA and Bacon BR: Nonalcoholic steatohepatitis: A proposal for grading and staging the histological lesions. Am J Gastroenterol 94: 2467-2474, 1999.

21. Brunt EM, Kleiner DE, Wilson LA, Belt P, Neuschwander-Tetri BA; NASH Clinical Research Network (CRN): Nonalcoholic fatty liver disease (NAFLD) activity score and the histopathologic diagnosis in NAFLD: Distinct clinicopathologic meanings. Hepatology 53: 810-820, 2011.

22. Qin J, Li R, Raes J, Arumugam M, Burgdorf KS, Manichanh C, Nielsen T, Pons N, Levenez F, Yamada T, et al: A human gut microbial gene catalogue established by metagenomic sequencing. Nature 464: 59-65, 2010.

23. Furet JP, Firmesse O, Gourmelon M, Bridonneau C, Tap J, Mondot S, Doré J and Corthier G: Comparative assessment of human and farm animal faecal microbiota using real-time quantitative PCR. FEMS Microbiol Ecol 68: 351-362, 2009.

24. Mariat D, Firmesse O, Levenez F, Guimarăes V, Sokol H, Doré J, Corthier G and Furet JP: The Firmicutes/Bacteroidetes ratio of the human microbiota changes with age. BMC Microbiol 9: 123 , 2009.

25. Da Silva HE, Teterina A, Comelli EM, Taibi A, Arendt BM, Fischer SE, Lou W and Allard JP: Nonalcoholic fatty liver disease is associated with dysbiosis independent of body mass index and insulin resistance. Sci Rep 8: 1466, 2018.

26. Boursier J, Mueller O, Barret M, Machado M, Fizanne L, Araujo-Perez F, Guy CD, Seed PC, Rawls JF, David LA, et al: The severity of nonalcoholic fatty liver disease is associated with gut dysbiosis and shift in the metabolic function of the gut microbiota. Hepatology 63: 764-775, 2016.

27. Adler M, Taylor S, Okebugwu K, Yee H, Fielding C, Fielding G and Poles M: Intrahepatic natural killer T cell populations are increased in human hepatic steatosis. World J Gastroenterol 17: $1725-1731,2011$
28. Tajiri K, Shimizu Y, Tsuneyama K and Sugiyama T: Role of liver-infiltrating $\mathrm{CD}^{+} \mathrm{CD} 56^{+}$natural killer T cells in the pathogenesis of nonalcoholic fatty liver disease. Eur J Gastroenterol Hepatol 21: 673-680, 2009.

29. Lotowska JM, Sobaniec-Lotowska ME and Lebensztejn DM The role of Kupffer cells in the morphogenesis of nonalcoholic steatohepatitis-ultrastructural findings. The first report in pediatric patients. Scand J Gastroenterol 48: 352-357, 2013.

30. Kazankov K, Tordjman J, Møller HJ, Vilstrup H, Poitou C, Bedossa P, Bouillot JL, Clement K and Grønbaek H: Macrophage activation marker soluble CD163 and non-alcoholic fatty liver disease in morbidly obese patients undergoing bariatric surgery. J Gastroenterol Hepatol 30: 1293-1300, 2015.

31. Cani PD and Delzenne NM: The role of the gut microbiota in energy metabolism and metabolic disease. Curr Pharm Des 15: 1546-1558, 2009.

32. Miquel S, Martín R, Rossi O, Bermúdez-Humarán LG, Chatel JM, Sokol H, Thomas M, Wells JM and Langella P: Faecalibacterium prausnitzii and human intestinal health. Curr Opin Microbiol 16: 255-261, 2013.

33. Zhang M, Qiu X, Zhang H, Yang X, Hong N, Yang Y, Chen H and Yu C: Faecalibacterium prausnitzii inhibits interleukin-17 to ameliorate colorectal colitis in rats. PLoS One 9: e109146, 2014.

34. Sokol H, Pigneur B, Watterlot L, Lakhdari O, BermúdezHumarán LG, Gratadoux JJ, Blugeon S, Bridonneau C, Furet JP, Corthier G, et al: Faecalibacterium prausnitzii is an anti-inflammatory commensal bacterium identified by gut microbiota analysis of Crohn disease patients. Proc Natl Acad Sci USA 105: 16731-16736, 2008

35. Mattace Raso G, Simeoli R, Russo R, Iacono A, Santoro A, Paciello O, Ferrante MC, Canani RB, Calignano A and Meli R: Effects of sodium butyrate and its synthetic amide derivative on liver inflammation and glucose tolerance in an animal model of steatosis induced by high fat diet. PLoS One 8: e68626, 2013.

36. Kles KA and Chang EB: Short-chain fatty acids impact on intestinal adaptation, inflammation, carcinoma, and failure. Gastroenterology 130 (Suppl 1): S100-S105, 2006. 